\title{
An Inhibitor of Histamine Release from Human Leukocytes
}

\author{
Michael T. Ketly and Arthur White \\ From the Infectious Diseases Division, Department of Medicine, Indiana \\ University Medical School, Indianapolis, Indiana 46202
}

A B S T R A C T Lysates of human leukocytes, prepared by ultrasonic disruption, contained heat-labile histaminereleasing factors. An inhibitor of histamine. release was generated from such lysates during thermal inactivation of the histamine-releasing activity. Lysates inactivated at $38^{\circ} \mathrm{C}$ for $60 \mathrm{~min}$ produced up to $90 \%$ inhibition of histamine release from human leukocytes. Heated lysates produced significant inhibition $(P<$ 0.001 ) of leukocyte histamine release induced by goat antihuman $\operatorname{IgE}$ ( $51 \pm 3 \%$ inhibition), compound 48/80 (69 $\pm 7 \%$ inhibition), and fresh leukocyte lysate (63 $\pm 6 \%$ inhibition).

Membrane ultrafiltration and gel-filtration chromatography suggested that the inhibitor was of less than 1,000 molecular weight. The partially purified inhibitor, eluted from Sephadex G-15 and lyophilized, contained no detectable protein or carbohydrate but produced 80 $90 \%$ inhibition of histamine release at a concentration of only $10 \mathrm{ng} / \mathrm{ml}$.

The histamine-releasing factors from lysates of purified suspensions of lymphocytes and granulocytes were fractionated on Sephadex G-25. A single peak of histamine-releasing activity with an estimated molecular weight of 5,000 was detected from each cell type. Incubation of the partially purified histamine-releasing factors at $38^{\circ} \mathrm{C}$ resulted in generation of an inhibitor of histamine release which was nearly identical to the inhibitor from crude lysates.

This natural inhibitor of histamine release, derived from human leukocytes, may provide an endogenous mechanism for the control of histamine release in inflammation.

\section{INTRODUCTION}

Histamine mediates the early stages of vasodilation and increased vascular permeability which characterize the acute inflammatory response (1). Since histamine is

\footnotetext{
Received for publication 22 June 1973 and in revised form 17 January 1974.
}

The Journal of Clinical Investigation Volume 53 May 1974-1343-1350 normally sequestered in the storage granules of tissue mast cells and circulating basophils, the control of histamine release may be central to the regulation of the inflammatory response. We recently described a possible endogenous mechanism for histamine release. In this system, factors in human leukocyte and platelet lysates release histamine from intact human leukocytes in vitro (2). Optimal histamine release occurs under physiological conditions, and intact, metabolically active cells are required $(3,4)$. The release reaction is specific, noncytotoxic, and complement independent, and it resembles a secretory process $(3,4)$. In addition, histamine release is modulated by cyclic AMP in a unique reversible system where agents which increase cyclic AMP stimulate reabsorption of previously released histamine (5). Our studies have also shown that leukocyte lysates release histamine in vivo using a canine model (6).

The chemical nature of the leukocyte histamine-releasing factors has remained obscure. Whereas the human platelet factors appear to be cationic protein, the leukocyte factors are not (2). Part of the difficulty in identifying these factors has been their marked lability: lysates rapidly lose their histamine-releasing activity even at room temperature. In the present studies we describe some preliminary characteristics of the heatlabile human leukocyte histamine-releasing factor. In addition, we describe an inhibitor of histamine release which is generated during thermal inactivation of the histamine-releasing activity at $38^{\circ} \mathrm{C}$.

\section{METHODS}

Preparation of leukocytes and leukocyte lysates. The leukocytes used in these studies were prepared from the blood of normal human donors by dextran sedimentation as previously described (2). Purified lymphocyte suspensions were prepared by a modification of the glass-bead column technique of Rabinowitz, described elsewhere (2). Purified granulocyte suspensions were prepared by sedimentation through a Ficoll-Hypaque cushion followed by dextran sedimentation as detailed by Böyum (7). Contaminating platelets and erythrocytes were removed from 


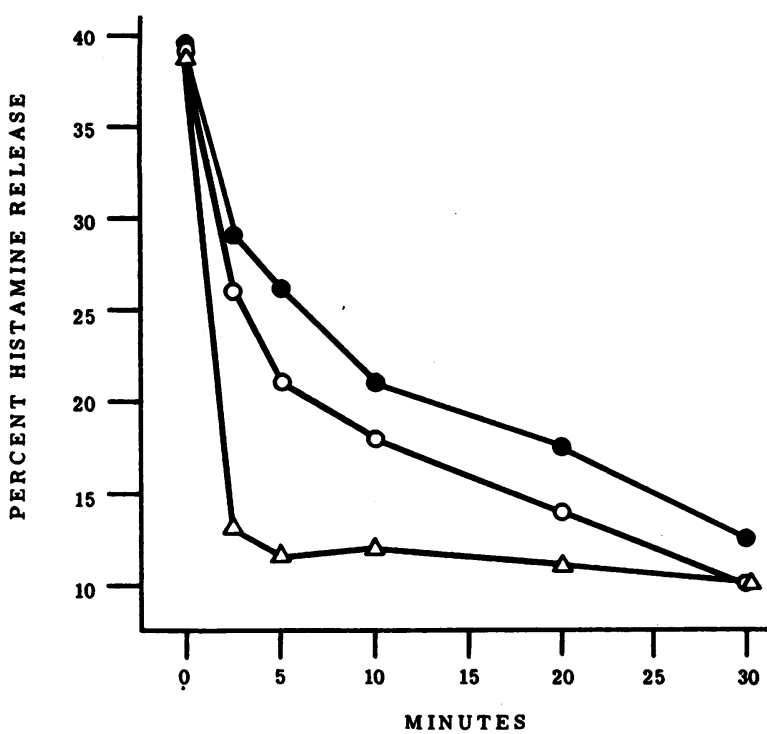

FIGURE 1 Time course of lysate heat inactivation. Leukocyte lysates were incubated at $38^{\circ}(\bullet), 56^{\circ}(O)$, or $100^{\circ} \mathrm{C}(\triangle)$ and samples were withdrawn at intervals for assays of histamine-releasing activity. Mean total leukocyte histamine concentration $0.111 \mu \mathrm{g} / \mathrm{ml}$.

the lymphocyte and granulocyte suspensions by lysis in Tris- $\mathrm{NH}_{4} \mathrm{Cl}$ (2).

Mixed leukocyte suspensions or suspensions of purified lymphocytes or granulocytes were washed and resuspended at a concentration of $1 \times 10^{8} / \mathrm{ml}$ in an isotonic salts solution containing human serum albumin (Tris A) (8). Lysates of these suspensions were prepared by ultrasonic disruption, as previously described (2). For histamine release assays, mixed leukocyte suspensions were washed in Tris A and resuspended at a concentration of $1 \times 10^{7} / \mathrm{ml}$ in Tris ACM (Tris A supplemented with $\mathrm{Ca}^{++}$and $\mathrm{Mg}^{++}$) (8).

Histamine release assay. The histamine-releasing activity of leukocyte lysates was determined by a previously described modification of the procedure of Lichtenstein and Osler $(2,8)$. Histamine was determined fluorometrically, as previously described (8).

Histamine release inhibition assay. 10 million leukocytes (final concentration $2.5 \times 10^{\circ} / \mathrm{ml}$ ) were incubated for 60 $\min$ at $38^{\circ} \mathrm{C}$ in $4.0 \mathrm{ml}$ Tris $\mathrm{ACM}$ containing the heated lysate inhibitor $(0.1-1.0 \mu \mathrm{g}$ lysate protein $/ \mathrm{ml})$. The cells were then collected by centrifugation and resuspended in $3.5 \mathrm{ml}$ Tris ACM. $0.5 \mathrm{ml}$ of a histamine-releasing agent was added to the resulting leukocyte suspensions. After 60 min incubation at $38^{\circ} \mathrm{C}$, the histamine released into the incubation mixture supernate was determined. Total leukocyte histamine was assayed after perchloric acid lysis (8), and the percent histamine release was determined based on these values for each experiment. In most experiments, the histamine-releasing agent was fresh leukocyte lysate which had been maintained in the cold to preserve histamine-releasing activity. The final concentration of fresh leukocyte lysate was adjusted to $0.25-1.0 \mu \mathrm{g}$ protein $/ \mathrm{ml}$ which provided optimal histamine release. In some experiments, compound $48 / 80$ (9), goat antihuman IgE (10) or staphylococcal antigen (cell-free extract of ultrasonically disrupted Staphylococcus aureus) (11) were used as histamine-releasing agents.
Control incubations not containing the heated lysate inhibitor were included in each experiment, and percent inhibition values were calculated based on these controls. Spontaneous histamine release in the absence of leukocyte lysate was monitored in each experiment, and it was always less than $5 \%$ of the total available histamine. All experiments were repeated at least three times using the cells of two or more donors.

Membrane ultrafiltration and column chromatography. Membrane ultrafiltration was carried out using Millipore (Millipore Corp., Bedford, Mass.) or Amicon (Amicon Corp., Lexington, Mass.) ultrafiltration systems equipped with membranes having a 1,000 mol wt exclusion limit. Gelfiltration chromatography was carried out on a column $(2.5$ $\times 40 \mathrm{~cm}$ ) with Sephadex G-25 equilibrated in a Tris-salts buffer system ( $\mathrm{pH} 7.4)$ of the following composition: Tris $(11.0 \mathrm{~g}), \mathrm{NaCl}(3.3 \mathrm{~g}), \mathrm{KCl}(0.35 \mathrm{~g}), \mathrm{HCl}(6.0 \mathrm{ml}) /$ liter distilled $\mathrm{H}_{2} \mathrm{O}$. The column was calibrated with cytochrome $c$ and cyanocobalamin. A second column $(1.5 \times 80$ $\mathrm{cm}$ ) contained Sephadex G-15 with an aqueous solvent system. 1-ml samples were applied to the columns, and 4$\mathrm{ml}$ fractions were collected. All separations were carried out at $4^{\circ} \mathrm{C}$.

Protein and carbohydrate assays. Protein was determined by the method of Lowry, Rosebrough, Farr, and Randall (12) using crystalline lysozyme as a standard. Total carbohydrate was determined by the method of McKelvy and Lee (13) using glucose as a standard.

\section{RESULTS}

Generation of heated lysate inhibitor. The heat lability of the leukocyte histamine-releasing activity was demonstrated by time-course studies. Leukocyte lysates were incubated at $100^{\circ}, 56^{\circ}$, or $38^{\circ} \mathrm{C}$, and samples were withdrawn at intervals for assays of histamine-releasing activity. The activity was rapidly destroyed at $100^{\circ}$ and $56^{\circ} \mathrm{C}$, and very little histamine-releasing activity remained after $30 \mathrm{~min}$ even when incubated at $38^{\circ} \mathrm{C}$ (Fig. 1). These results are typical of those obtained on several occasions throughout our studies of this system, and they demonstrate the marked heat lability of the human leukocyte histamine-releasing activity.

In another series of experiments, leukocyte lysates were incubated for $30 \mathrm{~min}$ at temperatures from $0^{\circ}$ to $100^{\circ} \mathrm{C}$. Leukocytes were then incubated with the resulting lysates $(0.1-1.0 \mu \mathrm{g}$ lysate protein $/ \mathrm{ml})$ for 60 $\min$. The leukocytes were removed by centrifugation, and the histamine released into the supernates was determined. The leukocytes from each sample were then incubated with fresh lysate, which had been kept frozen to preserve the histamine-releasing activity, and the histamine released into the incubation mixture supernates was again determined.

The lysates demonstrated reduced levels of histaminereleasing activity as the temperature of incubation was increased (Fig. 2), and 50\% inactivation was noted even after incubation at room temperature $\left(24^{\circ} \mathrm{C}\right)$. Of greater interest was the finding that the leukocytes exposed to the heated lysates demonstrated reduced 
levels of histamine release upon exposure to the active lysate. Leukocytes exposed to lysate which had been incubated at $38^{\circ} \mathrm{C}$ for $30 \mathrm{~min}$ demonstrated greater than $50 \%$ inhibition of histamine release. This experiment was repeated six times using the cells of three different donors with the same pattern of results although the maximum level of histamine release was 35$50 \%$ depending on the donor. In other experiments lysates incubated at $38^{\circ} \mathrm{C}$ for 60 min produced $90-100 \%$ inhibition of leukocyte histamine release.

To confirm the inhibitory activity of the heated lysates, suspensions of leukocytes were incubated at $4^{\circ}$ or at $38^{\circ} \mathrm{C}$ in the presence of lysate $(0.1-1.0 \mu \mathrm{g}$ lysate protein $/ \mathrm{ml}$ ) which had been incubated at $38^{\circ} \mathrm{C}$ for 60 min to generate inhibitory activity. Control leukocytes were incubated without heated lysate. Samples were withdrawn at intervals, and the leukocytes were collected by centrifugation. The cells were then incubated with fresh lysate, and histamine release was determined. The leukocytes exposed to heated lysate at both $4^{\circ}$ and $38^{\circ} \mathrm{C}$ demonstrated progressive impairment of histamine-releasing activity (Fig. 3). A 60-min exposure of leukocytes to heated lysate resulted in $90 \%$ inhibition of histamine release. The control cells not exposed to

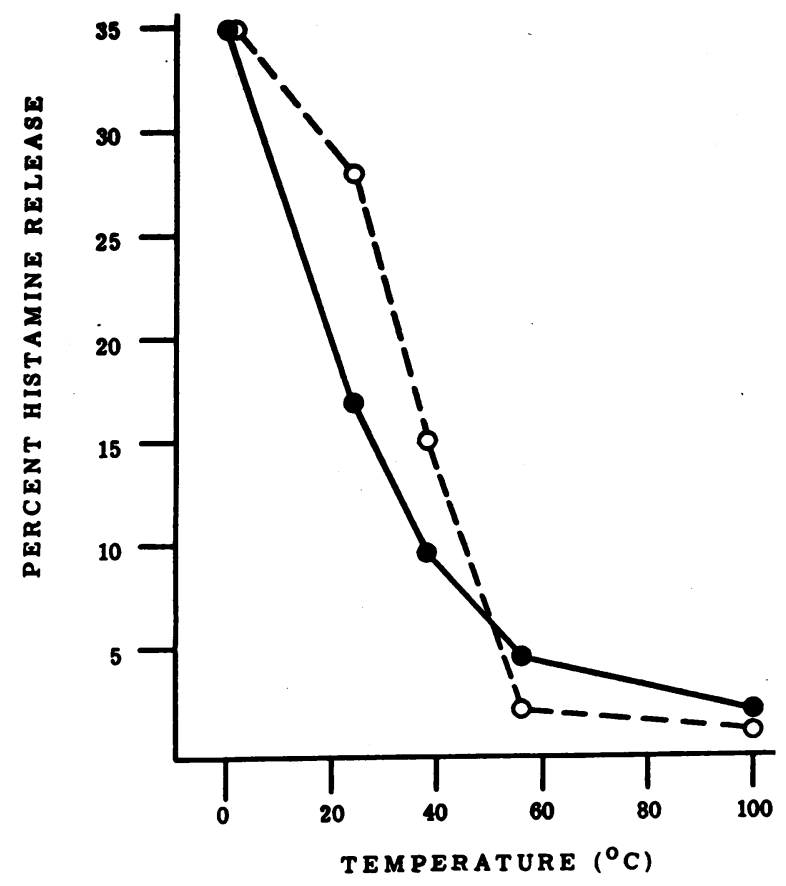

FIGURE 2 Generation of an inhibitor of histamine release during thermal inactivation of leukocyte lysates. Leukocyte lysates, incubated for $30 \mathrm{~min}$ at the temperatures indicated, were assayed for leukocyte histamine-releasing activity ( ). The leukocytes exposed to the heated lysates, were then challenged with fresh lysate, and histamine release was determined (O). Mean total leukocyte histamine concentration $0.122 \mu \mathrm{g} / \mathrm{ml}$.

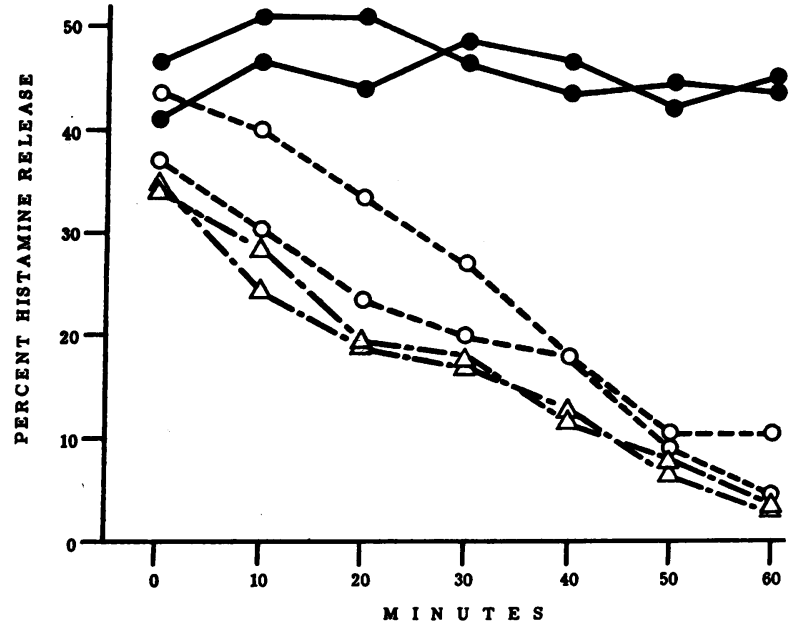

FIGURE 3 Time course of inhibition of histamine release by heat-inactivated leukocyte lysates. Leukocytes were incubated at $38^{\circ} \mathrm{C}$ in buffer ( $)$ or in heated leukocyte lysate (O) and at $4^{\circ} \mathrm{C}$ in heated leukocyte lysate $(\Delta)$. The cells were collected from aliquots at intervals and challenged with fresh leukocyte lysate to determine their histaminereleasing activity. Results using leukocytes from two different donors are presented. Mean total leukocyte histamine concentration $0.122 \mu \mathrm{g} / \mathrm{ml}$.

heated lysate maintained normal histamine-releasing activity. These results suggest that leukocyte lysates inactivated at $38^{\circ} \mathrm{C}$ contain an inhibitor of histamine release.

Effect of heated lysate on leukocyte viability. Leukocytes were incubated in buffer or in heated lysate in duplicate. The cells were removed by centrifugation and resuspended in $1 \%$ trypan blue or in fresh leukocyte lysate for determinations of viability and histamine release, respectively. The leukocytes not exposed to heated lysate demonstrated $98 \pm 1 \%$ (mean $\pm S D$ ) viability, as determined by trypan blue exclusion, and they produced $40 \pm 5 \%$ histamine release. The leukocytes incubated in heated lysate were $97 \pm 1 \%$ viable but demonstrated $9 \pm 7 \%$ histamine release. Therefore, the inhibition of histamine release by heated lysates does not appear to result from a cytotoxic effect.

Specificity of heated lysate inhibitor. Leukocytes were treated with heated lysate for $60 \mathrm{~min}$ at $38^{\circ} \mathrm{C}$. They were then collected by centrifugation and reincubated with a staphylococcal antigen extract (50 $\mu \mathrm{g} / \mathrm{ml})$, goat antihuman $\operatorname{IgE}\left(10^{-2}\right.$ dilution $)$, compound $48 / 80(50 \mu \mathrm{g} / \mathrm{ml})$, or fresh leukocyte lysate $(0.5$ $\mu \mathrm{g} / \mathrm{ml}$ ). After $60 \mathrm{~min}$ at $38^{\circ} \mathrm{C}$ in the presence of these test agents, leukocyte histamine release was determined. Control leukocytes, not exposed to heated lysate, were included for each histamine-releasing agent, and the percent inhibition of histamine release was calculated based on these controls. 


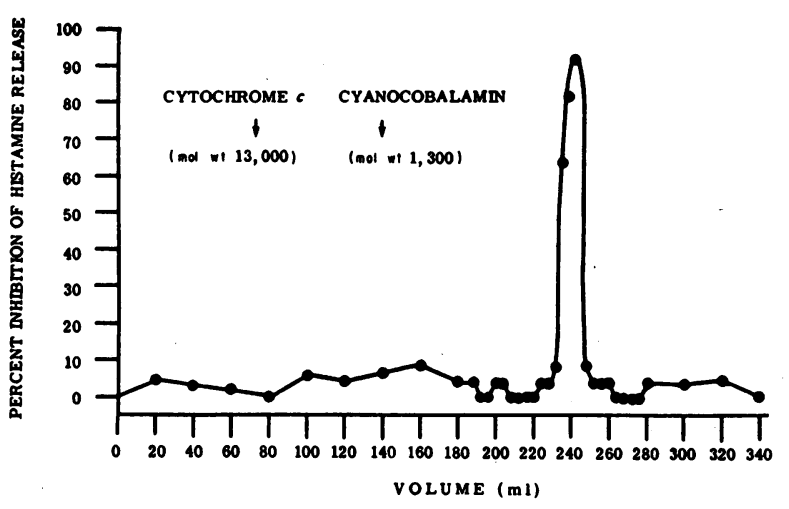

FIGURE 4 Chromatographic separation of the heated lysate inhibitor on Sephadex G-25 equilibrated with Tris salts buffer at $\mathrm{pH}$ 7.4. Fractions were diluted 1:1,000 and assayed for inhibition of leukocyte histamine release. Cytochrome $c$ and cyanocobalamin were used as calibrating markers. Control histamine release from leukocytes not exposed to inhibitor, $40 \%$. Mean total leukocyte histamine concentration $0.097 \mu \mathrm{g} / \mathrm{ml}$.

Exposure of leukocytes to heated lysate inhibited histamine release induced by three of the four agents tested (Table I). Histamine release induced by goat antihuman $\operatorname{IgE}$, compound $48 / 80$, and fresh leukocyte lysate was inhibited by 51,69 , and $63 \%$, respectively, in cells treated with heated lysate. The inhibition of histamine release was significant with a $P$ value of $<0.001$ for these three agents. Histamine release induced by staphylococcal antigen extract was not significantly affected by treatment of the leukocytes with heated lysate. Therefore, heated leukocyte lysates con-

TABLE I

Specificity of Inhibition of Histamine Release by Heated Leukocyte Lysates

\begin{tabular}{|c|c|c|c|}
\hline \multirow[b]{2}{*}{ Test agent } & \multicolumn{2}{|c|}{$\begin{array}{l}\text { Leukocyte histamine- } \\
\text { releasing activity* }\end{array}$} & \multirow[b]{2}{*}{ Inhibition $\ddagger$} \\
\hline & $\begin{array}{l}\text { Untreated } \\
\text { leukocytes }\end{array}$ & $\begin{array}{c}\text { Leukocytes } \\
\text { treated } \\
\text { with } \\
\text { heated } \\
\text { lysate }\end{array}$ & \\
\hline $\begin{array}{l}\text { Staphylococcal } \\
\text { antigen, } 50 \mu \mathrm{g} / \mathrm{ml}\end{array}$ & $62 \pm 6$ & $60 \pm 5$ & $\begin{array}{r}\% \\
5 \pm 1(\mathrm{NS})\end{array}$ \\
\hline $\begin{array}{l}\text { Goat antihuman } \\
\text { IgE, } 1 / 100 \mathrm{vol} / \mathrm{vol}\end{array}$ & $80 \pm 7$ & $38 \pm 2$ & $51 \pm 3(P<0.001)$ \\
\hline $\begin{array}{l}\text { Compound 48/80, } \\
50 \mu \mathrm{g} / \mathrm{ml}\end{array}$ & $30 \pm 3$ & $9 \pm 2$ & $69 \pm 7(P<0.001)$ \\
\hline $\begin{array}{l}\text { Leukocyte lysate, } \\
0.5 \mu \mathrm{g} / \mathrm{ml}\end{array}$ & $42 \pm 1$ & $16 \pm 3$ & $63 \pm 6(P<0.001)$ \\
\hline
\end{tabular}

* The percent of total available leukocyte histamine released into the incubation mixture supernates. Values are expressed as mean $\pm S E M$.

$\ddagger$ The percent inhibition of histamine release from the treated vs. untreated leukocytes. tain inhibitor (s) which block histamine release induced by a variety of agents.

Fractionation and partial characterization of heated lysate inhibitor. As a first step in the fractionation of the heated lysate inhibitory activity, mixed leukocyte lysates inactivated at $38^{\circ} \mathrm{C}$ for $60 \mathrm{~min}$ were subjected to membrane ultrafiltration. The results indicated that the inhibitory activity passed through membranes which exclude molecules of greater than 1,000 mol wt. In a typical separation, the protein concentration was reduced by a factor of six after ultrafiltration, but the inhibitory activity of the ultrafiltrate was essentially the same as the unfractionated lysate. Therefore, ultrafiltration provided a useful initial step in the purification of the inhibitory activity, and the results suggested that the inhibitor was of low molecular weight.

Chromatographic separation on Sephadex G-25 was carried out to further characterize the inhibitory activity. The ultrafiltrates of $38^{\circ} \mathrm{C}$ heated lysates were applied to a Sephadex G-25 column, and fractions, diluted $1: 1,000$, were assayed for inhibition of histamine release. A single peak of inhibitory activity was detected in each of five separations (Fig. 4). The elution profile of the inhibitory activity again suggested a low molecular weight confirming the impression gained from the ultrafiltration data.

In view of the very low molecular weight of the inhibitor, subsequent separations were carried out on Sephadex G-15. To obtain relatively salt-free preparations, leukocyte lysates were prepared in distilled water rather than Tris $A$, and the chromatographic separa-

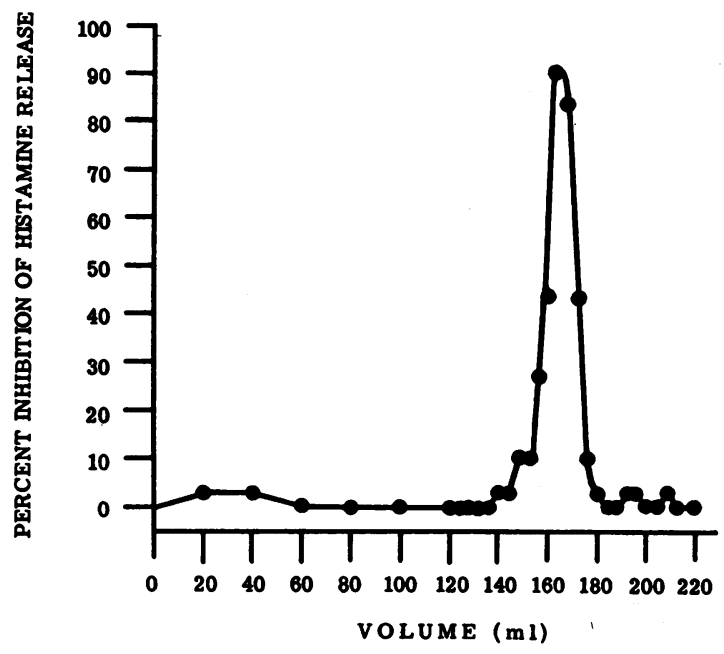

FIGURE 5 Chromatographic separation of the heated lysate inhibitor on Sephadex G-15 equilibrated with distilled water. Fractions were diluted 1:1,000 and assayed for inhibition of leukocyte histamine release. Control histamine release from leukocytes not exposed to inhibitor, $45.5 \%$. Mean total leukocyte histamine $0.104 \mu \mathrm{g} / \mathrm{ml}$. 
tions were carried out in water rather than buffer. These lysates were heated at $38^{\circ} \mathrm{C}$ for $60 \mathrm{~min}$, and ultrafiltrates were prepared as before. The ultrafiltrates were applied to the Sephadex G-15 column, and fractions, diluted 1:1,000, were assayed for inhibition of histamine release. Column chromatography on Sephadex G-15 failed to provide additional separation, and a single peak of inhibitory activity was again obtained in each of 10 separations (Fig. 5).

Assays of the active fractions from such separations had no detectable carbohydrate or protein. Therefore, seven column fractionations on Sephadex G-15 were carried out as described above, and the active fractions were combined and lyophilized. A total of $76 \mathrm{ml}$ of active column effluent produced only $1.66 \mathrm{mg}$ of dry material. This material was suspended at $200 \mu \mathrm{g} / \mathrm{ml}$ and assayed for protein, carbohydrate, and histamine. Only a trace of carbohydrate $(1.4 \mu \mathrm{g} / \mathrm{ml})$ and no protein or histamine was detected.

Leukocytes were incubated for $60 \mathrm{~min}$ with varied concentrations of this partially purified inhibitor. The cells were then collected by centrifugation and reincubated with fresh lysate to determine the percent inhibition of histamine release. This partially purified material produced $80-90 \%$ inhibition of histamine release at concentrations of less than $10 \mathrm{ng} / \mathrm{ml}$, and the $50 \%$ inhibitory concentration was approximately 0.25 $\mathrm{ng} / \mathrm{ml}$ (Fig. 6).

Generation of the inhibitor from the partially purified lymphocyte and granulocyte histamine-releasing factors.

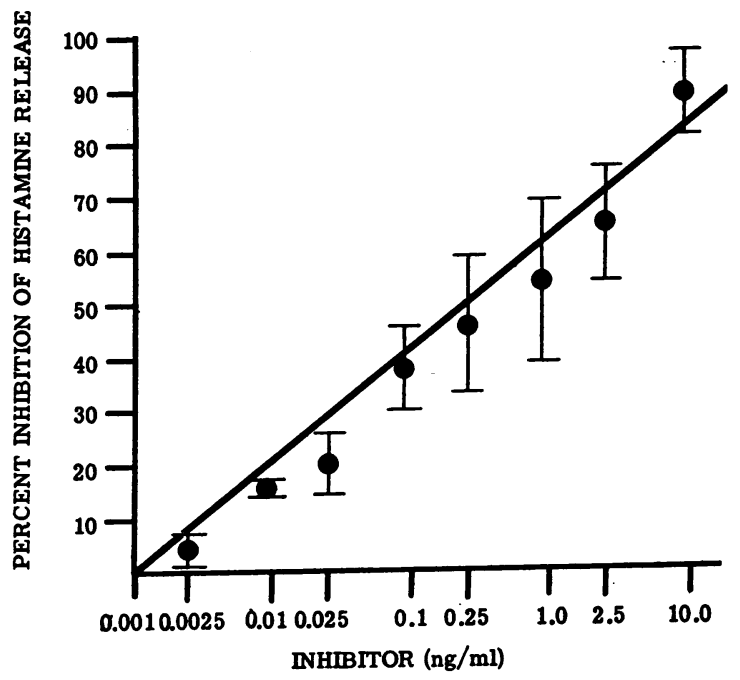

Figure 6 Dose-response curve for partially purified heated lysate inhibitor. Varied concentrations of the inhibitor were assayed for inhibition of histamine release induced by fresh leukocyte lysate. Control histamine release from leukocytes not exposed to inhibitor, $38 \pm 5 \%$. Mean total leukocyte histamine $0.097 \mu \mathrm{g} / \mathrm{ml}$. Values expressed as mean $\pm \mathrm{SE}$ for four determinations.

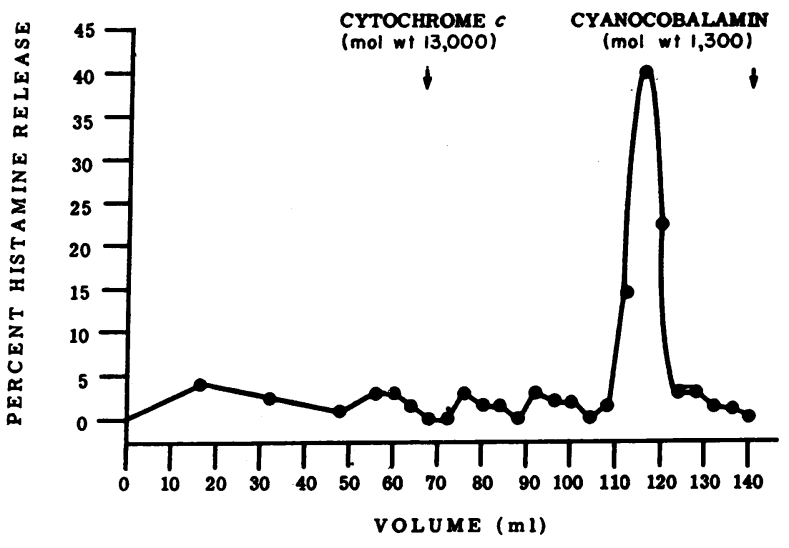

FIGURE 7 Chromatographic separation of the human granulocyte histamine-releasing factor on Sephadex G-25 equilibrated with Tris-salts buffer at $\mathrm{pH}$ 7.4. Fractions were diluted $1: 1,000$ and assayed for histamine-releasing activity. Cytochrome $c$ and cyanocobalamin were used as calibrating markers. Mean total leukocyte histamine concentration 0.082 $\mu \mathrm{g} / \mathrm{ml}$.

Since the lysates employed in these studies consisted of a mixture of lymphocytes and granulocytes, it was of interest to determine which type of cell contributed to the inhibitory activity. Lymphocyte and granulocyte suspensions of $95-100 \%$ purity were prepared, and they contained no erythrocytes and less than one platelet/two leukocytes. Lysates of these purified suspensions and of the standard mixed leukocyte suspensions were prepared, incubated at $38^{\circ} \mathrm{C}$ for $60 \mathrm{~min}$, and assayed for inhibition of leukocyte histamine release. The heated lysates of lymphocyte, granulocyte, and mixed leukocyte suspensions, diluted $1: 1,000$, inhibited histamine release by 64,80 , and $90 \%$, respectively.

Our previous studies revealed that lymphocytes and granulocytes also contain histamine-releasing factors (2). Therefore, studies were done to determine if the inhibitor of histamine release could be derived from the histamine-releasing factor. Lymphocyte and granulocyte lysates were subjected to gel filtration on Sephadex G-25, and the fractions were assayed for histaminereleasing activity. A single peak of activity was eluted between the 13,000 mol wt marker (cytochrome $c$ ) and the 1,300 mol wt marker (cyanocobalamin) (Fig. 7). The lymphocyte and granulocyte histamine-releasing factors had nearly identical elution profiles (Fig. 8). Mixtures of the most active fractions from the lymphocyte and granulocyte separations were rechromatographed, and a single peak of activity was again obtained (Fig. 8). Therefore, the human lymphocyte and granulocyte histamine-releasing factors appear to be the same, and they have an estimated molecular weight of approximately 5,000 daltons. 


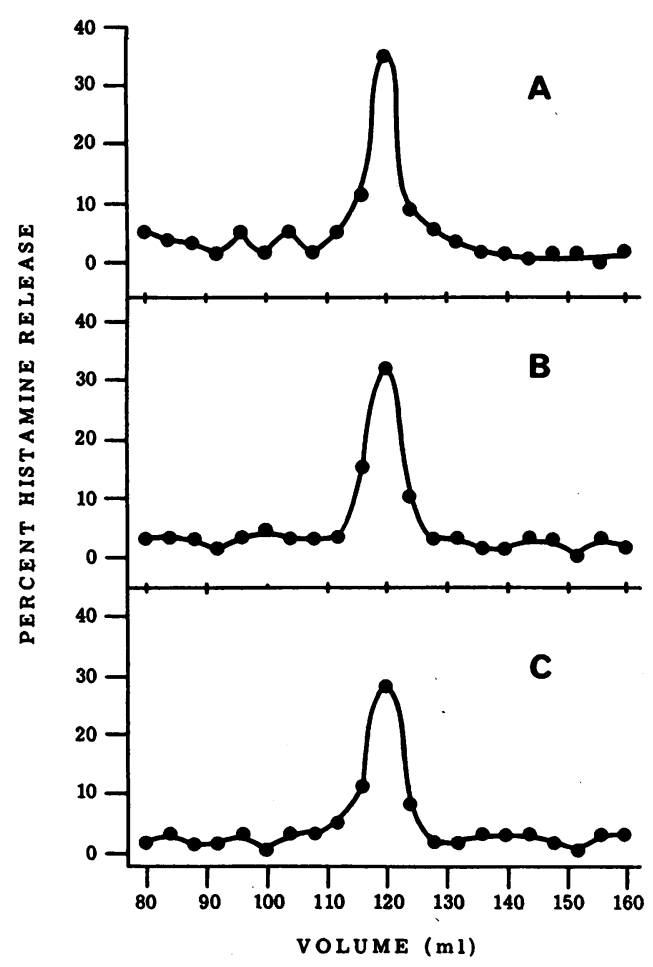

FIGURE 8 Comparative separation of the human lymphocyte and granulocyte histamine-releasing factors on Sephadex G-25 equilibrated with Tris-salts buffer at $\mathrm{pH} 7.4$. Fractions were diluted $1: 1,000$ and assayed for histaminereleasing activity. (A) Histamine-releasing activity from a lysate of purified granulocytes. (B) Histamine-releasing activity from a lysate of purified lymphocytes. (C) Histamine-releasing activity from a mixture of the most active fractions from A and B. Mean total leukocyte histamine concentration $0.085 \mu \mathrm{g} / \mathrm{ml}$.

These partially purified lymphocyte and granulocyte histamine-releasing factors were incubated at $38^{\circ} \mathrm{C}$ for $60 \mathrm{~min}$. The resulting preparations were then subjected to gel filtration on Sephadex G-25, and the fractions were assayed for inhibition of histamine release. A single peak of inhibitory activity was detected for each preparation, and the activity was eluted in the same position as that from the crude heated lysates (Fig. 9). The results sugest that the inhibitor of histamine release may be generated from the partially purified histamine-releasing factor.

\section{DISCUSSION}

Regulation of the extracellular histamine levels in vivo may be vital to the production and control of the acute inflammatory response. Since histamine is normally sequestered in the storage granules of tissue mast cells and circulating basophils, one aspect of its regulation concerns the liberation of histamine from these storage sites. Therefore, many important studies have ap- peared on the mechanisms of histamine release $(2,8-11$, 14).

The second aspect of the regulation of the histamine levels in inflammation concerns the mechanisms of limitation of the amounts of histamine in the extracellular spaces. This aspect of histamine regulation is probably of considerable importance in the control of inflammation, but definitive studies in this area have only recently begun to appear. Removal of extracellular histamine by enzymatic destruction or cellular uptake (3) would provide one type of regulation. However, a more efficient means of regulation would be to control histamine release.

Several mechanisms for the inhibition of histamine release have been investigated. The role of cyclic AMP as an inhibitor of histamine release has been fairly well established since agents which increase the intracellular levels of cyclic AMP inhibit a variety of histamine release systems $(3,14-16)$. In addition, substances which interfere with $\mathrm{Ca}^{++}$metabolism can inhibit the release process $(4,8,17,18)$. However, most of these inhibitors are exogenous substances, and to our knowledge, no natural, cell-derived inhibitors of histamine release have been described previously.

In the present studies we describe such a natural inhibitor which is generated from ultrasonically disrupted leukocytes during incubation at $38^{\circ} \mathrm{C}$. Incubation of intact leukocytes with inhibitory lysates results in progressive impairment of the ability of the cells to release histamine when challenged with a variety of agents (Fig. 3 and Table I). Thus, heated leukocyte lysates inhibit histamine release induced by antihuman $\operatorname{IgE}$, compound $48 / 80$, or fresh leukocyte lysate (Table I). Leukocyte lysate and antiIgE are known to release histamine from human leukocytes by an active process which resembles a secretory reaction $(4,5,9)$. Compound $48 / 80$ has been best studied in the rat mast cell system, and a similar active process seems to be involved in histamine release in this system (10). Although the mechanism of action of compound $48 / 80$ on human cells is not well understood, it is tempting to speculate that the inhibitor in heated leukocyte lysates may inactivate binding sites common to these three agents or inhibit some component of the release mechanism common to all three types of histamine release. The failure of the heated lysate factor to inhibit histamine release induced by staphylococcal antigens may reflect a different mechanism of histamine release such as release during phagocytosis or pinocytosis of the bacterial extract (11).

Although the exact mechanism of action of the haated lysate inhibitor is obscure, several of our studies provide information in this regard. The inhibition of histamine release from cells exposed to heated lysate at 
$4^{\circ} \mathrm{C}$ (Fig. 3) suggests that membrane-binding phenomena may be involved. The studies of trypan blue exclusion suggest that leukocyte viability is not affected by the inhibitor, and selective damage to basophils would seem to be excluded by the lack of histamine release during exposure to the inhibitor. In addition, cells treated with the inhibitor are still capable of histamine release when challenged with a bacterial extract (Table I). These studies suggest that the mechanism of action of this inhibitor of histamine release is not cytotoxic and that binding of the inhibitor to the leukocyte membrane may be involved.

Another possible explanation for the action of the heated lysate inhibitor could involve the phenomenon of desensitization. Desensitization occurs in immune histamine release when cells are exposed to antigen under suboptimal conditions. Such cells are rendered less capable of histamine release upon subsequent exposure to antigen under optimal conditions $(19,20)$. The result is apparent inhibition of histamine release. Desensitization is difficult to exclude in our system, but it does not seem to apply in the strict sense because the cells are exposed to the inhibitor under conditions which are optimal for histamine release. Nevertheless, a phenomenon similar to desensitization could be implicated in our system.

The inhibitor of histamine release in heated leukocyte lysates appears to be of low molecular weight since it readily passes through membrane ultrafilters which exclude molecules of greater than $1,000 \mathrm{~mol}$ wt. The inhibitory activity was eluted from Sephadex G-25 considerably later than cyanocobalamin which has an approximate mol wt of 1,300 daltons (Fig. 4). It was also retarded by Sephadex G-15 (Fig. 5). These findings suggest that the heated lysate inhibitor has a molecular weight of less than 1,000 daltons. Preliminary analysis on the mass spectrometer of the partially purified inhibitor eluted from Sephadex G-15 revealed a possible mol wt of 355 daltons.

Our studies suggest that the inhibitor of histamine release may be derived from the leukocyte histaminereleasing factor. The histamine-releasing factors from human lymphocytes and granulocytes were eluted as identical, single peaks from Sephadex G-25, and they had an estimated mol wt of 5,000 (Figs. 7 and 8). This is in contrast to our earlier studies which indicated that these factors sedimented at $100,000 \mathrm{~g}$ (2). This discrepancy may be explained by binding of the low molecular weight histamine-releasing factors to larger molecules during centrifugation. Such binding has been demonstrated for a histamine-releasing factor derived from rabbit leukocytes (21).

Incubation of these partially purified histamine-releasing factors at $38^{\circ} \mathrm{C}$ produced inhibitors of hista-

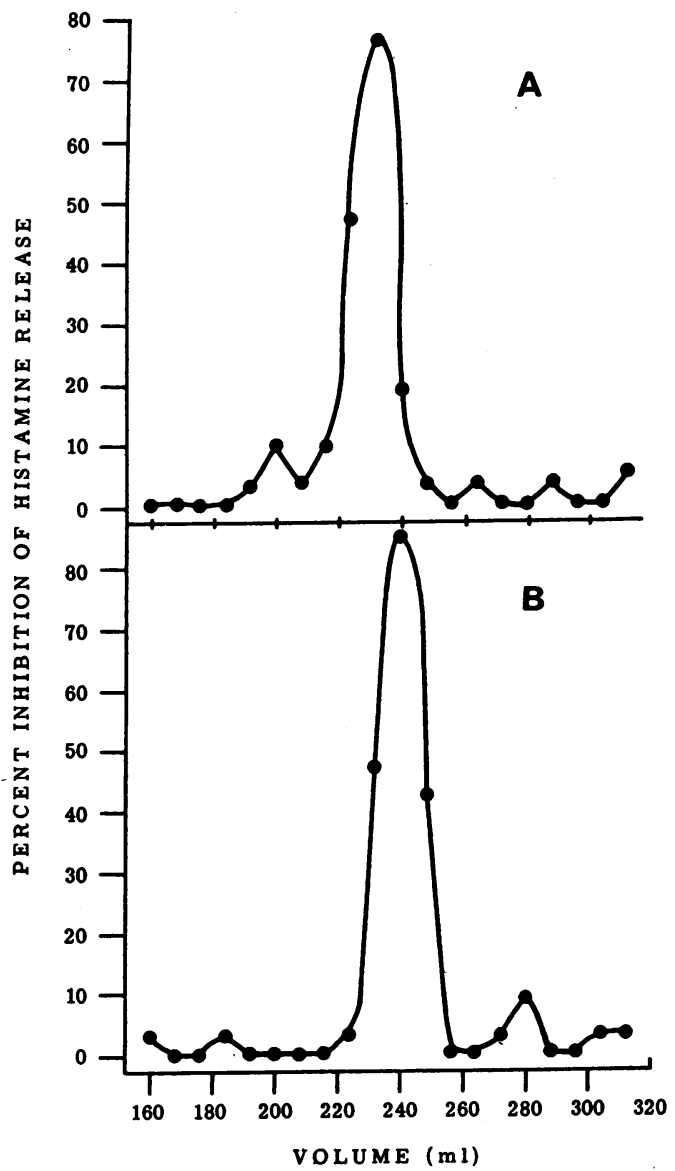

FIGURE 9 Chromatographic separation of the inhibitor of histamine release from lymphocytes and granulocytes on Sephadex G-25 equilibrated with Tris-salts buffer at $\mathrm{pH}$ 7.4. The partially purified histamine-releasing factor from granulocytes (A) and lymphocytes (B) was heated at $38^{\circ} \mathrm{C}$ for $60 \mathrm{~min}$ and then applied to the column. Fractions were diluted $1: 1,000$ and assayed for inhibition of histamine release. Control histamine release from leukocytes not exposed to inhibitor, $35 \%$. Mean total leukocyte histamine $0.085 \mu \mathrm{g} / \mathrm{ml}$.

mine release which were nearly identical to those from the crude leukocyte lysates (Fig. 9). These results suggest that the inhibitor of histamine release in heated leukocyte lysates may be a fragment of the leukocyte histamine-releasing factor which is generated during its inactivation at $38^{\circ} \mathrm{C}$.

The chemical nature of the heated lysate inhibitor remains obscure at this time. The very small amounts of purified material available for analysis limit attempts to identify its chemical nature. No protein or carbohydrate was detected by the methods employed, and only nonspecific absorption was detected on spectral analysis in the ultraviolet range. Infrared spectrometry revealed only the presence of amino groups. The ac- 
tivity was rapidly destroyed by dilute acid, but was relatively stable in dilute alkali. Whatever the nature of this inhibitor, it is remarkably potent, producing up to $90 \%$ inhibition of histamine release at a concentration of only $10 \mathrm{ng} / \mathrm{ml}$.

In view of the very small amounts of material required to produce inhibition, it is tempting to suggest a role for a second messenger, such as cyclic AMP, which might amplify the inhibitory effect $(19,22)$. Histamine is one cyclic AMP-active agent which could play a role in this system, but the purified inhibitor did not contain detectable histamine. Cyclic AMP itself might also be considered, but much greater concentrations are usually required to exert an effect $(3,14-16)$. In addition, preliminary experiments revealed that the cyclic AMP-active agent, theophylline, and the heated lysate inhibitor produced only additive inhibition of histamine release. Therefore, we have no evidence at present to implicate the cyclic AMP system in the inhibition of histamine release by heated leukocyte lysates.

The results presented suggest that human lymphocytes and granulocytes contain a heat-labile, low molecular weight histamine-releasing factor. An inhibitor of histamine release is generated during thermal inactivation of this histamine-releasing factor. This inhibitor appears to be of extremely low molecular weight, and it could be a fragment of the histamine-releasing factor which is released during heat-inactivation.

The possible implications for such an inhibitor of histamine release in vivo are evident. Leukocytes are early inhabitants of most inflammatory foci, and since the inhibitor is readily generated at $38^{\circ} \mathrm{C}$, it could limit histamine release in vivo. Inhibition of histamine release by this human leukocyte factor could provide an efficient means for controlling that part of the inflammatory response mediated by histamine.

\section{ACKNOWLEDGMENTS}

We are grateful to Mr. Ted Summers and Mrs. Betty Dunston for expert technical assistance.

This work was supported by Training Grant AI 00343 and Research Grant AI 09781 from the National Institute of Allergy and Infectious Disease, National Institutes of Health, Bethesda, Md.

\section{REFERENCES}

1. Miller, R. L., and K. L. Melmon. 1970. The related roles of histamine, serotonin and bradykinin in the pathogenesis of inflammation. Ser. Haematol. 3: 5.

2. Kelly, M. T., R. R. Martin, and A. White. 1971. Mediators of histamine release from human platelets, lymphocytes and granulocytes. J. Clin. Invest. 50: 1044.

3. Kelly, M. T., and A. White. 1973. Histamine release induced by human leukocyte lysates: implication of a specific, complement-independent, non-cytotoxic reaction. Infect. Immun. 8: 8 .

4. Kelly, M. T., and A. White. 1973. Histamine release induced by human leukocyte lysates: effect of metabolic inhibitors and carbohydrates. Infect. Immun. 8: 15.

5. Kelly, M. T., and A. White. 1973. Histamine release induced by human leukocyte lysates: reabsorption of previously released histamine after exposure to cyclic AMP-active agents. J. Clin. Invest. 52: 1834.

6. Kelly, M. T., R. 'E. Brashear, R. R. Martin, and A. White. 1971. Histamine release in the dog after leukocyte lysate injection. Infect. Immun. 4: 228.

7. Böyum, A. 1968. Isolation of mononuclear cells and granulocytes from human blood. Scand. J. Clin. Lab. Invest. 21 (Suppl. 97) : 77.

8. Lichtenstein, L. M., and A. G. Osler. 1964. Studies on the mechanisms of hypersensitivity phenomena. IX. histamine release from human leukocytes by ragweed pollen antigen. J. Exp. Med. 120: 507.

9. Thon, I. L., and B. Uvnas. 1967. Degranulation and histamine release, two consecutive steps in response of rat mast cells to compound 48/80. Acta Physiol. Scand. 71: 303 .

10. Ishizaka, K., and T. Ishizaka. 1969. Immune mechanisms of reversed type reaginic hypersensitivity. $J$. Immunol. 103: 588 .

11. Martin, R. R., and A. White. 1969. The in vitro release of leukocyte histamine by staphylococcal antigens. J. Immunol. 102 : 437.

12. Lowry, O. H., N. J. Rosebrough, A. L. Farr, and R. J. Randall. 1951. Protein measurement with the Folin phenol reagent. J. Biol. Chem. 193: 265.

13. McKelvy, J. F., and Y. C. Lee. 1969. Microheterogeneity of the carbohydrate group of Aspergillus oryzae $\alpha$-amylase. Arch. Biochem. Biophys. 132: 99.

14. Orange, R. P., W. G. Austen, and K. F. Austen. 1971. Immunological release of histamine and slow-reacting substance of anaphylaxis from human lung. I. modulation by agents influencing cellular levels of cyclic $3^{\prime}, 5^{\prime}$ adenosine monophosphate. J. Exp. Med. 134: 136s.

15. Bourne, H. R., L. M. Lichtenstein, and K. L. Melmon. 1972. Pharmacologic control of allergic histamine release in vitro: evidence for an inhibitory role of cyclic $3^{\prime}, 5^{\prime}$-adenosine monophosphate in human leukocytes. $J$. Immunol. 108: 695.

16. Assem, E. S. K., and H. O. Schild. 1971. Inhibition of the anaphylactic mechanism by sympathomimetic amines. Int. Arch. Allergy Appl. Immunol. 40: 576.

17. Tidball, M. E. 1967. Heparin inhibition of histamine release and its relation to calcium. Fed. Proc. 26: 231 .

18. Foreman, J. C., and J. L. Mongar. 1972. Dual effect of lanthanum on histamine release from mast cells. Nat. Nere Biol. 240: 255

19. Schild, H. O. 1968. Mechanism of anaphylactic histamine release. In Biochemistry of the Acute Allergic Reactions. K. F. Austen and E. L. Becker, editors. F. A. Davis Co., Philadelphia. 99.

20. Lichtenstein, L. M. 1971. The immediate allergic response: In vitro separation of antigen activation, decay and histamine release. J. Immunol. 107: 1122.

21. Benveniste, J., P. M. Henson, and C. G. Cochrane. 1972. Leukocyte-dependent histamine release from rabbit platelets: the role of $\operatorname{IgE}$, basophiles, and a platelet-activating factor. J. Exp. Med. 136: 1356.

22. Lichtenstein, L. M. 1968. Mechanism of allergic histamine release from human leukocytes. In Biochemistry of the Acute Allergic Reactions. K. F. Austen and E. L. Becker, editors. F. A. Davis Co., Philadelphia. 153. 